\title{
Influência do alongamento passivo em três repetições de 30 segundos a cada 48 horas em músculo sóleo imobilizado de ratos
}

\author{
Thiago Menon', Luana Muriel Casarolli², Núbia Broetto Cunha², Leandro de Souza²,
}

Paulo Henrique Muleta Andrade ${ }^{2}$, Carlos Eduardo de Albuquerque ${ }^{3}$ e Gladson Ricardo Flor Bertolini ${ }^{4}$

\section{RESUMO}

O músculo esquelético tem a propriedade de adaptar-se a diferentes estímulos, alterando o número de sarcômeros em série, de acordo com o comprimento a que está submetido. Este trabaIho tem como objetivo comparar as adaptações de peso e comprimento do músculo sóleo de ratos, além de estimativa do total de sarcômeros em série, quando submetidos a alongamento intermitente durante imobilização em plantiflexão. Foram utilizados 24 ratos (Wistar) machos de $14 \pm 2$ semanas de idade, divididos em 4 grupos: $C(n=6)$ - controle; $A(n=6)$ - músculo sóleo esquerdo (MSE) alongado; I $(n=6)$ - MSE imobilizado; IA ( $n=6)$ - MSE imobilizado e alongado. O protocolo utilizado foi 3 séries de alongamento com duração de 30s a cada 48h; e período total de imobilização de 21 dias. Foram comparadas as variações observadas entre os músculos sóleus direito (MSD) e o MSE com relação a peso muscular, comprimento muscular e estimativa do número de sarcômeros em série (ENSS), através da contagem em 300 $\mu \mathrm{m}$. Nas variáveis analisadas ao comparar o MSD (controle) e o MSE (submetido a alongamento e/ou imobilização) foram observados: peso muscular: $C=-1,59 \%,(p=0,67) ; A=+5,41 \%(p=0,05) ; I=$ $-41,48 \%(p=0,01) ; \mid A=-32,46 \%(p=0,01)$; comprimento muscular: $C=-2,63 \%(p=0,43) ; A=+7,54 \%(p=0,07) ; I=-12,74 \%$ $(p=0,01) ; I A=-10,42 \%(p=0,11) ; E N S S: C=-3,81 \%(p=0,09)$; $A=+2,73 \%(p=0,56) ;|=-12,20 \%(p=0,01) ;| A=-12,21 \%(p=$ $0,21)$. Conclui-se que o alongamento durante a imobilização preservou o comprimento muscular e a quantidade de sarcômeros em série, mas não evitou a perda do peso muscular.

\section{ABSTRACT \\ Influence of passive stretching in three 30-second sets at every 48 hours in immobilized soleum muscle of rats}

The skeletal muscle has the property to adapt to different stimuli, alternating the number of sarcomeres in series, according to the length to which it is submitted to. This investigation has the aim to compare weight and length adaptations of the soleus muscle in rats, besides the total estimate of the sarcomeres in series, when submitted to intermittent stretching during immobilization

1. Fisioterapeuta, formado pela Universidade Estadual do Oeste do Paraná (UNIOESTE), Campus de Cascavel - Paraná.

2. Fisioterapeuta formada pela UNIOESTE.

3. Docente do curso de Fisioterapia da UNIOESTE.

4. Mestre em Engenharia Biomédica pela UFTPR.

Aceito em 13/6/07.

Endereço para correspondência: Gladson Ricardo Flor Bertolini, Rua Luiz Vilwock, 125, B. Nova cidade - 85803-177 - Cascavel, PR. Tels.: (045) 324-4470, 9112-1033, 220-3157 (Unioeste).

E-mail: gladson_ricardo@uol.com.br, gladson@unioeste.br
Palavras-chave: Imobilização. Alongamento muscular. Sarcômeros em série. Keywords: Immobilization. Muscular stretching. Sarcomeres in series.

in plantarflexion. Twenty-four $14 \pm 2$ weeks old Wistar male rats were used. They were divided in 4 groups, namely: $C(n=6)-$ control; $A(n=6)$ - stretched left soleus muscle (LSM); I $(n=6)$ immobilized left soleus muscle; IA $(n=6)$ - immobilized and stretched LSM. The used protocol was of 3 stretching sets with $30 \mathrm{~s}$ duration at every $48 \mathrm{~h}$, and total immobilization period of 21 days. The variations observed were compared between right soleus muscle (RSM) and LSM concerning muscular weight, muscular length and estimate of number of sarcomeres in series (ENSS), through counting in $300 \mu \mathrm{m}$. In the analyzed variables, when RSM (control) and LSM were compared (submitted to stretching and/or immobilization) the following were observed: muscular weight: $C$ $=-1.59 \%(p=0.67) ; A=+5.41 \%(p=0.05) ; 1=-41.48 \%(p=$ $0.01) ; I A=-32.46 \%(p=0.01) ;$ muscular length: $C=-2.63 \%(p=$ $0.43) ; A=+7.54 \%(p=0.07) ; I=-12.74 \%(p=0.01) ; I A=-10.42 \%$ $(p=0.11) ;$ ENSS: $C=-3.81 \%(p=0.09) ; A=+2.73 \%(p=0.56) ; 1$ $=-12.20 \%(p=0.01) ; \mid A=-12.21 \%(p=0.21)$. It is concluded that stretching during immobilization has preserved muscular length and the amount of sarcomeres in series; however, it did not prevent muscular weight loss.

\section{INTRODUÇÃO}

As fibras musculares esqueléticas apresentam capacidade de adaptação a determinados estímulos, como o exercício físico, imobilização, alterações das condições hormonais e nutricionais. Todo esse processo tem suas repercussões para a prática clínica(1).

Após curto período de imobilização, ocorrem mudanças no tecido conjuntivo; principalmente o aumento de colágeno, perda de capilares, redução no tamanho e alterações morfológicas das fibras musculares, além de diminuição do número de sarcômeros em série. A posição na qual o músculo é mantido tem importante fator para o acúmulo de tecido conectivo e para a rigidez muscular ${ }^{(2-3)}$, existem, porém, controvérsias a respeito das alterações na proporção do colágeno tipo I e III nos músculos imobilizados, havendo relatos de diminuição dos níveis. Contudo, o alongamento passivo poderia combater estes efeitos ${ }^{(4)}$.

Devido às propriedades viscoelásticas do tecido conectivo, o alongamento muscular é geralmente utilizado com objetivo de aumentar a flexibilidade muscular. Porém, tanto a manutenção prolongada em posição de alongamento, quanto à imobilização em posição de encurtamento muscular (através de imobilização), produzem alterações no componente contrátil muscular, causando aumento e diminuição no número de sarcômeros em série, respectivamente(5). 
A literatura demonstra que não há consenso sobre o método, a intensidade, a duração e a freqüência do alongamento para prevenção do encurtamento muscular ou melhora da flexibilidade ${ }^{(6-8)}$, sendo que diferentes métodos podem, em períodos diferentes, demonstrar ganhos de flexibilidade semelhantes. Porém, mesmo com uma lacuna no conhecimento presente, o alongamento é usado em programas de aptidão física e reabilitação porque se acredita que influencie positivamente no desempenho e prevenção de lesões, além do fato que encurtamentos e contraturas podem causar limitações na amplitude de movimento restringindo a ação normal do músculo(9-10).

Estudos utilizando diferentes protocolos de alongamento muscular em humanos, como os de Knight et al.(9), Aalto et al..(11), Kerrigan et al.(12), e, Chan, Hong e Robinson ${ }^{(10)}$ demonstraram ganhos no arco de movimento após períodos variáveis de duração. Thom et al. ${ }^{(13)}$ investigaram os efeitos de 10 dias de imobilização em quadríceps sobre a área de secção transversal, força e a regulação de cálcio no retículo sarcoplasmático através de biópsias musculares em 8 sujeitos saudáveis. Observaram que a área muscular, força e captura do cálcio diminuíram significativamente no período. Esses trabalhos demonstram a capacidade de plasticidade do músculo esquelético humano.

Estímulos mecânicos aplicados a um músculo estão relacionados à expressão gênica de fatores de crescimento pelo próprio músculo, fato que regula a síntese protéica no tecido muscular(14). Williams ${ }^{(15)}$ relata que quando o músculo é imobilizado em posição de alongamento, ocorre hipertrofia sarcomeral em série, com aumento do comprimento da fibra muscular pela adição de novos sarcômeros.

O alongamento produz tensão nos sarcômeros o que pode induzir a pouca sobreposição dos filamentos contráteis, através da adição de novos sarcômeros pode-se resultar em um comprimento ótimo restaurado, portanto, o número de sarcômeros não é fixo(10).

O presente trabalho justifica-se na tentativa de esclarecimento de dúvidas sobre a resposta do alongamento passivo na prevenção do encurtamento muscular e no trofismo sarcomeral em animais de experimentação, visando consubstanciar futuros estudos terapêuticos. O objetivo foi analisar os efeitos do alongamento passivo em músculo sóleo de ratos, encurtados ou não por imobilização, tendo como variáveis estudadas: a) o peso muscular; b) o comprimento muscular; c) a estimativa do número de sarcômeros em série nas fibras musculares.

\section{MÉTODOS}

No presente estudo foram utilizados 24 ratos Wistar, machos, com peso corporal médio de 303,5 $\pm 27,04 \mathrm{~g}$, com idade de $14 \pm 2$ semanas, obtidos no Biotério da Universidade Estadual do Oeste do Paraná - campus Cascavel. Os animais foram agrupados e mantidos em gaiolas plásticas (3 ratos em cada), em condições ambientais controladas (luminosidade: 12 horas de ciclo claro/escuro, temperatura $24 \pm 1^{\circ} \mathrm{C}$ ), com livre acesso à água e ração, seguindo preceitos éticos de experimentos com animais. A amostra foi dividida aleatoriamente em 4 grupos, sendo sacrificados após 21 dias de experimento, para a dissecação e análise dos músculos sóleos direito e esquerdo.

- Grupo $1(\mathrm{C})$ - $(\mathrm{n}=6)$ : mantido solto na gaiola sem qualquer alongamento passivo ou restrição de movimento, por um período de 3 semanas consecutivas.

- Grupo $2(A)$ - ( $n=6)$ : o músculo sóleo esquerdo foi alongado passivamente a cada $48 \mathrm{~h}$ em dorsiflexão, durante 3 semanas consecutivas, sem qualquer tipo de imobilização.

- Grupo 3 (I) - (n = 6): apenas imobilizado em flexão plantar, durante 3 semanas consecutivas, não recebendo qualquer forma de alongamento no decorrer do período.

- Grupo $4(\mid \mathrm{A})$ - $(\mathrm{n}=6)$ : a pata posterior esquerda destes animais foi imobilizada em flexão plantar máxima, produzindo encur- tamento muscular do sóleo, e a cada 48h, os animais receberam alongamento passivo em dorsiflexão por 3 semanas consecutivas.

Para realizar o procedimento de imobilização, os animais foram previamente anestesiados com éter etílico. O aparato de imobilização visava obter o encurtamento do músculo sóleo esquerdo, sendo utilizado um modelo desenvolvido no Laboratório de Neurociências do departamento de Fisioterapia da UFSCar ${ }^{(16)}$. A articulação tibiotársica foi imobilizada em máxima flexão plantar com algodão e fita adesiva e posteriormente colocou-se o modelo de imobilização. Os animais eram observados diariamente, devido à possibilidade de ocorrer danos no aparato de imobilização.

Para se efetuar a técnica de alongamento no músculo sóleo, os animais foram previamente anestesiados com éter etílico e a imobilização retirada. Sem a imobilização, a articulação tibiotársica foi mantida em flexão dorsal máxima, durante o período de alongamento, que consistiu de 3 séries de 30 segundos, com intervalo de repouso de 30 segundos entre as séries. Após o tempo de alongamento muscular passivo, o modelo de imobilização foi recolocado e o músculo mantido novamente em posição de encurtamento máximo (flexão plantar) durante mais 48h.

Ao término do experimento, todos os animais dos 4 grupos foram pesados, anestesiados e, os músculos sóleos direito (MSD) e esquerdo (MSE) dissecados. Durante esse procedimento os músculos foram periodicamente gotejados com solução fisiológica de $\mathrm{NaCl}(0,9 \%)$ visando evitar o ressecamento tecidual, que em seguida foram limpos e pesados isoladamente em balança analítica. Ainda sob efeito do anestésico, os animais foram sacrificados em guilhotina. A seguir os músculos sóleos foram fixados em placas de isopor e imersos em solução de glutaraldeido $(2,5 \%)$ durante 3h e colocado em ácido nítrico (30\%) para hidrólise do tecido conjuntivo, permanecendo neste por 2 dias e, em seguida, armazenado em solução de glicerol $(50 \%)^{(17)}$.

Posteriormente, o músculo foi estendido em superfície plana e seu comprimento mensurado com auxílio de paquímetro da marca Tecnolub, sendo este procedimento realizado sempre pelo mesmo examinador. $\mathrm{O}$ isolamento das fibras foi realizado colocandose o músculo em uma placa de petri e com o auxílio de lupa (Micronah), as fibras foram isoladas através de pinças com pontas ultrafinas. As fibras isoladas foram montadas em lâmina histológica em meio contendo gelatina-glicerina (Sigma), e protegidas com lamínula para posterior observação em microscópio de luz (com objetiva de 100 vezes em imersão) (Olympus). Para a contagem do número de sarcômeros de cada músculo foram retiradas 8 fibras inteiras de tendão a tendão do músculo, porém, foram avaliadas cinco fibras no decorrer de $100 \mu \mathrm{m}$ em 3 campos não consecutivos, totalizando $300 \mu \mathrm{m}$. A contagem do número de sarcômeros foi realizada sempre pelo mesmo examinador, visando evitar tendências.

O cálculo utilizado para estimar o total de sarcômeros em série na fibra foi regra de três simples, onde o total de sarcômeros da fibra muscular corresponde ao número de sarcômeros em $300 \mu \mathrm{m}$ multiplicado pelo comprimento do músculo. Visto que segundo Weineck ${ }^{(18)}$, na maioria dos músculos esqueléticos, cada fibra se estende por todo comprimento do músculo, utilizou-se como base para analisar o total de sarcômeros na fibra o comprimento do músculo, sendo desta forma, diferente do realizado por Coutinho et al. ${ }^{(19)}$ e Gomes et al. ${ }^{(20)}$ em que analisaram o comprimento da fibra muscular.

As variáveis analisadas (peso muscular, comprimento muscular e número de sarcômeros em série) foram avaliadas pela comparação entre os resultados obtidos nos músculo das patas esquerdas (imobilizado e/ou alongado) e direita (intacto), em cada grupo experimental, utilizando a estatística descritiva (descrevendo em percentagem, média e desvio-padrão) e pelo teste $t$ de Student pareado, sendo considerado significante $p<0,05$, com uso do programa Excell 2000 do Microsoft Office. 


\section{RESULTADOS}

Os resultados das variáveis analisadas, peso muscular, comprimento muscular e estimativa do total de sarcômeros em série são apresentados a seguir, respectivamente nas tabelas 1, 2 e 3 .

TABELA 1

Peso muscular dos grupos experimentais

C

A

I

IA

Peso

$\operatorname{MSD}(\mathrm{g})$

$0,1570 \pm 0,0118 \quad 0,1646 \pm 0,0780 \quad 0,1536 \pm 0,0176 \quad 0,1411 \pm 0,0116$

Peso

MSE (g)

$0,1545 \pm 0,0120$

$0,1735 \pm 0,0100$

$0,0899 \pm 0,0159$

$0,0953 \pm 0,0225$

Variação

$$
-1,59 \%
$$

$5,41 \%$

$-41,48 \%$

$32,46 \%$

Valor

de "p"

$p=0,0495^{*}$

$p=0,0002^{*}$

$p=0,0101^{*}$

C - grupo controle; A - grupo alongado; I - grupo imobilizado; IA - grupo imobilizado e alongado; MSD - músculo sóleo direito; MSE - músculo sóleo esquerdo.

* Diferenças estatisticamente significativas.

\section{TABELA 2}

Comprimento muscular dos grupos experimentais

C

$\begin{array}{cc}1,90 \pm 0,16 & 1,99 \pm 0,67 \\ 1,85 \pm 0,06 & 2,14 \pm 0,12 \\ -2,63 \% & 7,54 \% \\ p=0,4293 & p=0,0668\end{array}$
IA

Comp MSD $(\mathrm{cm})$

Comp MSE (cm)

Variação

Valor de "p"
I

\section{A}

$2,04 \pm 0,06$

$1,78 \pm 0,19$

$-12,74 \%$

$\mathrm{p}=0,0106^{*}$
$1,92 \pm 0,09$

$1,72 \pm 0,22$

$-10,42 \%$

$p=0,1053$

C - grupo controle; A - grupo alongado; I - grupo imobilizado; IA - grupo imobilizado e alongado; MSD - músculo sóleo direito; MSE - músculo sóleo esquerdo.

* Diferença estatisticamente significativa.

\section{Tabela 3}

Estimativa do número de sarcômeros em série dos grupos experimentais

C

A

I

IA

ENSS

MSD

$9310,00 \pm 716,54 \quad 8360,65 \pm 365,55 \quad 9122,88 \pm 650,13 \quad 8263,68 \pm 582,27$

ENSS

MSE

$8942,67 \pm 519,74 \quad 8588,53 \pm 969,77 \quad 7371,57 \pm 599,85 \quad 7254,88 \pm 1019,64$

$\begin{array}{lcccc}\text { Variação } & 3,81 \% & 2,73 \% & 19,20 \% & 12,21 \% \\ \text { Valor } & p=0,0892 & p=0,5556 & p=0,0017^{*} & p=0,2139 \\ \text { de "p" } & p=0\end{array}$

C - grupo controle; A - grupo alongado; I - grupo imobilizado; IA - grupo imobilizado e alongado; MSD - músculo sóleo direito: MSE - músculo sóleo esquerdo.

MSD - músculo sóleo direito; MSE - mús
* Diferença estatisticamente significativa.

Com relação ao peso muscular foi observado maior peso no MSE no grupo A e menores pesos nos grupos I e IA no MSE em relação ao MSD.

Quanto ao comprimento muscular, houve apenas diferença significativa no grupo I, o qual apresentou menor comprimento no MSE $(p<0,05)$ em comparação ao MSD.

Para a estimativa de sarcômeros em série, observou-se novamente diferença significativa apenas no grupo I, com menor número de sarcômeros no MSE $(p<0,05)$ quando comparado ao MSD.

\section{DISCUSSÃO}

Estudos em animais demonstram a capacidade de adaptação muscular para diferentes estímulos, ocorrendo alterações na quantidade de tecido conjuntivo, no comprimento, tamanho e peso das fibras musculares ${ }^{(5,21)}$.

O alongamento passivo estimula a síntese de proteínas e adição de sarcômeros ao longo da fibra muscular através da libera-

ção de fatores de crescimento. Fato demonstrado por Yang et al.(22) que após alongar músculos mantidos em posição de encurtamento demonstraram aumento da liberação IGF-I e expressão de RNAm para proteínas musculares. Gomes et al. ${ }^{(20)} \mathrm{em}$ protocolo de alongamento 1 vez por semana, apontaram que não houve aumento no peso muscular do grupo apenas submetido a alongamento sem imobilização, nem do total de sarcômeros em série. Coutinho et al.(19) com protocolo de alongamento a cada 3 dias, também não observaram aumento de peso, porém com relação ao número de sarcômeros em série obtiveram variação significante.

No presente estudo, o grupo submetido apenas a alongamento passivo apresentou variações nos três parâmetros avaliados (peso, comprimento e total de sarcômeros), sendo que o único a demonstrar variação significativa foi o peso muscular. Coutinho et al.(19) ao avaliar a área de secção transversa das fibras musculares submetidas apenas a alongamento, observaram aumento na área destas fibras; este fato pode explicar o ganho de peso muscular observado nos resultados apresentados anteriormente.

Smith et al. ${ }^{(23)}$ observaram que a imobilização em plantiflexão de patas de coelhos induz alterações morfológicas de atrofia do sóleo por reduções na massa e na área de secção transversa das fibras musculares.

Tabary et al.(5) observaram que após 4 semanas de imobilização em posição de alongamento ocorreu um aumento em $20 \%$ no número de sarcômeros em série. A imobilização em posição de encurtamento muscular promoveu a diminuição em $40 \%$ do número de sarcômeros em série ao longo da fibra, ocorreu aumento do tamanho dos sarcômeros e diminuição de peso muscular.

Esse fato pode ser observado no presente estudo, no qual o grupo apenas submetido à imobilização apresentou diminuição significante no peso, comprimento muscular, e diminuição do número de sarcômeros em série, corroborando com a literatura acerca da plasticidade do sóleo ao imobilizá-lo em posição de encurtamento. Ao observar o grupo controle, em que não ocorreu qualquer tipo de intervenção, pode-se observar a ausência de diferenças significantes nas variáveis analisadas, o que sugere principalmente para o grupo apenas imobilizado a plasticidade do tecido muscular frente à imobilização.

Williams et al. (2) relataram que ao alongar diariamente um músculo encurtado por imobilização, houve prevenção na deposição de tecido conjuntivo no tecido muscular. Coutinho et al..(19) afirmam que sessões periódicas de alongamento muscular passivo, realizadas a cada $72 \mathrm{~h}$, por 40 min, não impediram, mas amenizaram a atrofia das fibras musculares do sóleo.

No presente estudo o grupo imobilizado e alongado demonstrou que o alongamento passivo por 30s repetido por 3 vezes não conseguiu impedir uma diminuição do peso muscular de forma significativa, porém, as perdas tanto do comprimento muscular, quanto a estimativa do número de sarcômeros em série lapesar de ao comparar com o membro contralateral apresentarem diminuições) não foram significativas, indicando que o protocolo de alongamento proposto foi eficaz ao evitar a hipotrofia sarcomeral. Fato que segundo Gomes et al.(20) não ocorre em protocolos de 40 min de duração aplicados apenas 1 vez por semana.

Como principal limitação do presente estudo, salienta-se que como havia diferenças iniciais de peso corporal nos diferentes grupos, tornou-se difícil realizar comparações inter-grupos; além do fato, que se deve ter cautela em extrapolações de estudos realizados com animais para os efeitos da imobilização em humanos.

Ao término do presente estudo concluiu-se que: a imobilização produziu alterações nas três variáveis estudadas, com diminuições significativas em peso e comprimento muscular, além da diminuição na estimativa do total de sarcômeros em série. No grupo em que se associou o alongamento à imobilização, o comprimento muscular e a contagem de sarcômeros em série foram preservados; e no grupo em que se utilizou apenas o alongamento observou-se apenas aumento considerável no peso muscular. Ou seja, 
o alongamento muscular em curta duração pode ser um fator auxiliar na prevenção da perda de sarcômeros em série em indivíduos que necessitem de imobilização prolongada, diminuindo conseqüências da hipotrofia relacionadas à imobilização, como a perda na velocidade de contração.

Todos os autores declararam não haver qualquer potencial conflito de interesses referente a este artigo.

\section{REFERÊNCIAS}

1. Salvini TF. Plasticidade e adaptação postural dos músculos esqueléticos. In: MARQUES AP. Cadeias Musculares - Um programa para ensinar avaliação fisioterapêutica global. São Paulo: Manole; 2000. p. 3-14.

2. Williams PE, Catanese T, Lucey EG, Goldspink G. The importance of strecth and contractile activity in the prevention of connective tissue accumulation in muscle. J Anat. 1988;158:109-14.

3. Kannus $P$, Jozsa L, Järvinen TLN, Wvist M, Vieno $T$, Järvinen TAH, et al. Free mobilization and low to high-intensity exercise in immobilization-induced muscle atrophy. J Appl Physiol. 1998;84(4):1418-24.

4. Ahtikoski AM, Koskinen SOA, Virtanen P, Kovanen V, Takala TES. Regulation of synthesis of fibrillar collagens in rat skeletal muscle during immobilization in shortned and lengthened positions. Acta Physiol Scand. 2001;172:131-40.

5. Tabary JC, Tabary C, Tardieu C, Tardieu G, Goldspink G. Physiological and structural changes in the cat's soleus muscle due to immobilization at different lengths by plaster casts. J Physiol. 1972;224:231-44.

6. Alter MJ. Ciência da Flexibilidade. 2a ed. Porto Alegre: Artmed; 1999.

7. Feland JB, Myrer JW, Schulthies SS, Fellingham GW, Measom GW. The effect of duration of stretching of the hamstring muscle group for increasing range of motion in people age 65 years or older. Physical Therapy. 2001;81:1110-7.

8. Krivickas LS. Treinamento de flexibilidade. In: Frontera WR, Dawson DM, Slovir DM, editores. Exercício físico e reabilitação. Porto Alegre: Artmed; 2001. p. 95113.

9. Knight CA, Rutledge CR, Cox ME, Acosta M, Hall SJ. Effect of superficial heat, deep heat, and active exercise warm-up on the extensibility of the plantar flexors. Physical Therapy. 2001;81(6):1206-14.
10. Chan SP, Hong Y, Robinson PD. Flexibility and passive resistance of the hamstrings of young adults using two different static stretching protocols. Scand $J$ Med Sci Sports. 2001;11:81-6.

11. Aalto TJ, Airaksinen O, Härkönen TM, Arokoski JP. Effect of passive stretch on reproducibility of hip range of motion measurements. Arch Phys Med Rehabil. 2005;86:549-57.

12. Kerrigan DC, Xenopoulos-Oddsson A, Sullivan MJ, Lelas JJ. Effect of a hip flexorstretching program on gait in the elderly. Arch Phys Med Rehabil. 2003;84:1-6.

13. Thom JM, Thompson MW, Ruell PA, Bryant GJ, Fonda JS, Harmer AR, et al. Effect of 10-day cast immobilization on sarcoplasmic reticulum calcium regulation in humans. Acta Physiol Scand. 2001;172:141-7.

14. Minamoto VB, Salvini TF. O músculo como um órgão de secreção hormonal de secreção hormonal regulado pelo estímulo mecânico. Rev Bras Fisioter. 2001; 5(2):87-94.

15. Williams PE. Use of intermittent stretch in prevention of serial sarcomere loss in immobilized muscle. Annals of the Rheumatic Diseases. 1990:49:316-7.

16. Coutinho EL, Gomes ARS, França CN, Salvini TF. A new model for immobilization of rat hind limb. Braz J Med Biol Res. 2002;35:1-4.

17. Williams PE. Effect of intermittent strech on immobilized muscle. Annals of the Rheumatic Diseases. 1988;47:1014-6.

18. Weineck J. Biologia do esporte. São Paulo: Manole; 2000.

19. Coutinho EL, Gomes ARS, França CN, Oishi J, Salvini TF. Effect of passive stretching on the immobilized soleus muscle fiber morphology. Braz J Med Biol Res. 2004;37:1853-61.

20. Gomes ARS, Coutinho EL, França CN, Polonio J, Salvini TF. Effect of one stretch a week applied to the immobilized soleus muscle on rat muscle fiber morphology. Braz J Med Biol Res. 2004;37:1473-80.

21. Gajdosik RL. Passive extensibility of skeletal muscle: review of literature with clinical implications. Clinical Biomechanics. 2001;16:87-101.

22. Yang S, Alnaqeeb M, Simpson H, Goldspink G. Changes in muscle fibre type, muscle mass and IGF-I gene expression in rabbit skeletal muscle subjected to stretch. J Anat. 1997;190(4):613-22.

23. Smith HK, Maxwell L, Martyn JA, Bass JJ. Nuclear DNA fragmentation and morphological alterations in adult rabbit skeletal muscle after short-term immobilization. Cell Tissue Res. 2000;302:235-41. 